\title{
The Role of Toxic Leadership and Perceived Organizational Support on Academic Staff's Psychological Distress
}

\section{Aishah Tamby Omar, Ungku Norulkamar Ungku Ahmad}

To Link this Article: http://dx.doi.org/10.6007/IJARBSS/v10-i12/8388

DOI:10.6007/IJARBSS/v10-i12/8388

Received: 20 November 2020, Revised: 14 December 2020, Accepted: 27 December 2020

Published Online: 05 December 2020

In-Text Citation: (Omar \& Ahmad, 2020)

To Cite this Article: Omar, A. T., \& Ahmad, U. N. U. (2020). The Role of Toxic Leadership and Perceived Organizational Support on Academic Staff's Psychological Distress. International Journal of Academic Research in Business and Social Sciences, 10(12), 958-980.

\section{Copyright: (c) 2020 The Author(s)}

Published by Human Resource Management Academic Research Society (www.hrmars.com)

This article is published under the Creative Commons Attribution (CC BY 4.0) license. Anyone may reproduce, distribute, translate and create derivative works of this article (for both commercial and non-commercial purposes), subject to full attribution to the original publication and authors. The full terms of this license may be seen at: http://creativecommons.org/licences/by/4.0/legalcode

Full Terms \& Conditions of access and use can be found at http://hrmars.com/index.php/pages/detail/publication-ethics 


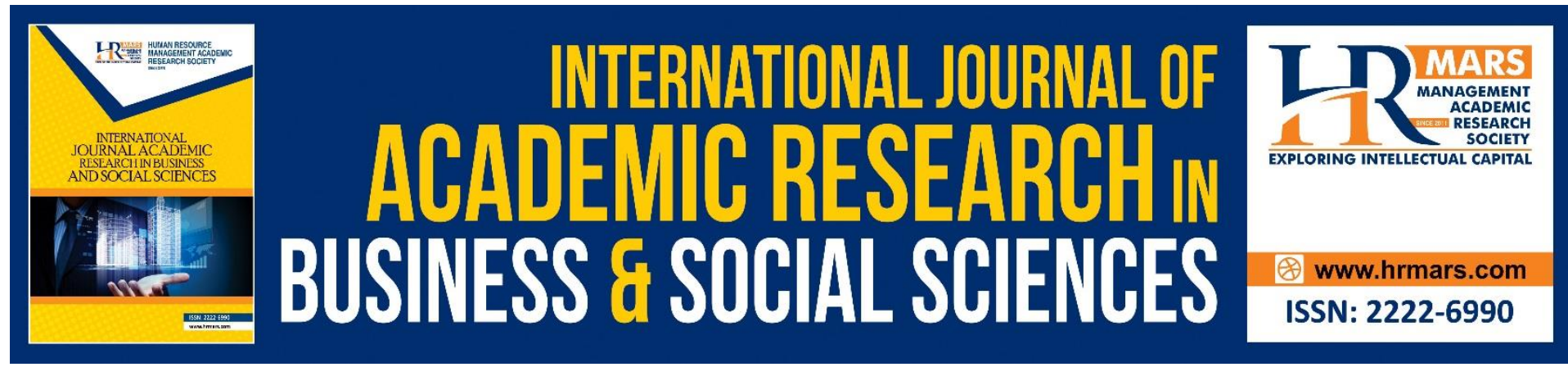

\title{
The Role of Toxic Leadership and Perceived Organizational Support on Academic Staff's Psychological Distress
}

\author{
Aishah Tamby Omar \\ Centre for the Promotion of Knowledge and Language Learning, Universiti Malaysia Sabah, \\ Jalan UMS, 88400 Kota Kinabalu, Malaysia. \\ Email: aisyah@ums.edu.my
}

Ungku Norulkamar Ungku Ahmad

Azman Hashim International Business School, Universiti Teknologi Malaysia, 81310, Skudai, Johor Bahru, Malaysia.

\begin{abstract}
This study examines the impact of toxic leadership on academic staff's psychological distress in the Malaysian context. Also, the moderating role of perceived organizational support is explored. A questionnaire was utilized to gather the data $(n=450)$ for this research. The multistage sampling technique combines cluster sampling and a simple random sampling involving academic staff from a public university in Malaysia. The SMART PLS-SEM version 3.2.7. was used to analyze the data. Based on the structural model's standardized path coefficients from the PLS results, toxic leadership profoundly influenced employees' psychological distress. However, perceived organizational support was an insignificant moderator of the impact between toxic leadership and psychological distress. The empirical research findings address the gap in the overall body of literature regarding Toxic Leadership Theory, such as the psychological distress and perceived organizational support. Hence, it provides an insight into toxic leadership study that has a few examined in previous research. Toxic leadership phenomenon can be used by the organization to better understand the dark side of leadership style, improve employee knowledge about toxic leadership and emotional coping strategy. Successful preventing toxic leadership is seen as an advantage for organizations that can promote a healthy work environment and a quality leader.
\end{abstract}

Keywords: Academic Staff, Perceived Organizational Support, Psychological Distress, Toxic leadership, Partial Least Squares (PLS).

\section{Introduction}

To remain competitive, employee well-being must be a focal point for an organization (Hong et al., 2019; Rubenstein et al., 2018). A large and growing body of literature is concerned about the mental state of employees as it affects human life (Katherine et al.,2014). Without specifying the form of organizations and geographical borders, mental health issues at the workplace have now become an outbreak (Kelloway, 2017; Dobson et al., 2019). Besides, 
Nada and Ruth (2020) revealed that these mental health problems had spread globally. One factor that constitutes a potential threat to employees' well-being is toxic leadership (LipmanBlumen, 2005; Asha \& Snigdha, 2019; Whicker, 1996; Lubit, 2004). Previous literature suggests that interest in exploring employee mental well-being appears to be strong when toxic leadership exists in organizations.

Toxic leadership nowadays is an increasingly crucial phenomenon in the study of dark side leadership (Schyns \& Schilling, 2013; Lipman-Blumen, 2010; Webster et al., 2016). Lipman-Blumen (2005) was the first ground-breaking study to investigate Toxic Leadership Theory systematically. She had identified that toxic leadership as a process in which the leader possesses destructive behaviour and dysfunctional personal characteristics, inflict severe and enduring harm on the individuals, organizations, communities, and nations (Lipman-Blumen, 2005). Drawing based on a psychology perspective, toxic leaders also being labelled as having psychopathy traits and personality disorder (Goldman, 2009; Mitchell \& Elizabeth, 2009), and their presence can be harmful to the organization (Whicker, 1996). Given the definitions mentioned so far, one may suppose that there is toxicity in every sense of the behaviour term.

During a leadership position, toxic leaders exercise violations, mislead, play to the fears, fail to mentors, ignore competence, and isolate their followers (Lipman-Blumen, 2010). They also build an atmosphere of fear and intimidation in which employees refuse to speak up. A healthy individual can get weak, anxious, and depressed in some situations when dealing with a toxic leader (Vickers, 2006). A previous study shows that 94 per cent of the workers have worked with toxic leaders in their careers (Mitchell \& Elizabeth, 2009). Nevertheless, as organizations realize that individual leaders are aggressive to employees, they are looking for information on how such toxic leadership behaviours impact the workplace.

Toxic leadership affects performance at the organizational and individual levels (Natesha \& Imani, 2019). In a horrific situation, individuals can have an overactive emotional response to their leader's toxicity and bring this negative feeling into their everyday lives. Thus, employees who undergo behaviour patterns of toxic leaders suffer detrimental outcomes, such as psychological distress (Asha \& Snigdha, 2019). Mitchell and Elizabeth (2009) found that 92 per cent of employees who have been exposed to toxic leaders are suffering from psychological distress. The importance of investigating the effect of the toxic leader's behaviour on emotional distress has been observed from various organizations across the world (Goldman, 2008). Besides, psychological distress issues are currently at the centre of educational research due to the increasing trend towards the prevalence of emotional disorders and the cost of prevention associated with these symptoms. Thus, expanding the Toxic Leadership Theory by adding psychological distress is a crucial variable for studying toxic leadership outcomes.

Also, when assessing the variance in employee psychological distress resulting from toxic leadership, other factors must be taken into account. According to the Organizational Support Theory (Eisenberger et al.,1986; Eisenberger \& Stinglhamber, 2011; Shore \&Shore, 1995), employee emotional health is ultimately caused by inadequate organizational support specifically for the well-being of employees (Bronston et al., 2017). Thus, this research expanded the Toxic Leadership Theory by added Organizational Support Theory as a moderator for employee's psychological distress. While the present study suggests that toxic leadership is more effective in terms of employee psychological distress, it is still essential to consider organizational support for employee psychological distress (Rhoades \& Eisenberger, 2002). Ebrahim et al. (2019) found that, to some extent, organizational support could mitigate 
emotional distress among employees. Webster et al. (2016) point out that Human Resource Manager advice and counselling may potentially reduce employees' psychological distress, particularly in dealing with toxic leaders. Pahlevan et al. (2018) argue that the higher the organization's aid, the lower the level of employees suffering from mental health distress. For employees, their feeling of belonging, respect, esteem, emotional support raises their morale and is strongly influenced by organizational support.

Furthermore, the available perceived organizational support literature has yet another limitation that only discusses in a constructive leadership style (Arnold, 2017), while research studies analyzing perceived organizational support from a toxic leadership perspective are very scarce (Webster et al., 2016; Bekir, 2020). Hence, adding Organizational Support Theory gives a new direction on reducing employee mental health. Based on the earlier proposition about toxic leadership, this research aims to:

1. examine the relationship between toxic leadership and psychological distress.

2. examine the perceived organizational support as a moderator for the relationship between toxic leadership and psychological distress.

\section{Literature Review}

This study used the Toxic Leadership Theory as the guiding principle in the proposed theoretical model in understanding the behaviour of toxic leaders and perceived organizational support in influencing psychological distress among academic staff. The extended variables are corroborated with Chen and Kao's (2009) view and Chua and Murray (2015), who suggested that emotional well-being is one area in which the theory might be extended.

\section{The theoretical foundation of toxic leadership}

Many organizations have paid close attention to organizational deviance (Ahmad Bodla et al., 2019). Organization as an unhealthy atmosphere has arisen from the fact that organizations have not diligently conveyed values, which is why toxic behaviour is developing and increasing within the organization (Appelbaum \& Roy, 2007). Therefore, the leaders who used their toxic power could harm the organization and individual. Lipman-Blumen (2005) defines toxic leaders as a person with destructive behaviour and dysfunctional personal characteristics, inflicting severe and long-lasting harm to his followers.

Lipman-Blumen emphasizes toxic leadership's core features based on intentionality, intensity, physical/verbal or non-verbal actions, and outcomes. Loraleigh and Karen (2011); Tepper and Henle (2011); Lipman-Blumen (2005) take the view that it is difficult to assess the real intent of the leader and that toxic leaders do not behave consistently. As a result, none of the scholars describes the intention and unintended actions for the concept of toxic leadership. This is because the leader's toxic intentions and the results of the conduct are not intrinsically related.

Intensity is commonly referred to as toxic leaders responsible for a certain level of violence against followers. According to Lipman-Blumen (2005), the level of violence can vary from very mild to very severe. Thus, each degree of violence may have different outcomes. Also, Dong et al. ( 2012) found that a leader with high violence could lead to distress and low staff productivity.Therefore, to acknowledge the prevalence of toxic leadership in the organization, attention must be paid to the degree of intensity through severe and longlasting harm to followers. 
Despite various behaviours, the difficulties in selecting the best-defined toxic leader behaviour are still under debate. An example of current theories, the Social Construction Theory (Hunt, 1984), proposed that followers' views of leadership behaviour differ based on their demographics. It is challenging to select the exact toxic behaviour that emerges in the organization. However, Dotlich and Cairo (2003) suggested that one of the negative behaviours observed and frequently displayed through destructive behaviours is sufficient to identify a toxic leader's presence in their organization. Thus, Lipman-Blumen (2005) proposed a general concept, such as destructive behaviour, to classify toxic leadership.

Finally, Lipman-Blumen ( 2005) described toxic leadership outcomes in more neutral terms, such as harmful. It is widely agreed that results should be based on presumed nature rather than specific impacts, which can contribute to the incorrect inclusion of behaviours (Thoroughgood et al., 2012).

\section{Toxic leadership and psychological distress}

Lipman's toxic leadership theory is based mainly on the concept of misbehaviour, similar to the destructive and abusive leadership that both concerned violent conduct. It also includes actions against the well-being of the organization and the followers. Toxic leaders and employee relations can also be regarded as an inverse relationship (Wu \& Hu, 2009). The values, attitude, and behaviour of a leader influence followers' well-being as a consequence of the interaction. When the leader shows a harmful engagement, the employee feels worthless and demeaning, showing a poor performance (Ozlem et al., 2017).

Leadership affects the dyadic, team, and personal relationships within the organization and impact on psychological well-being (Fahie, 2019). According to Asha and Snigdha (2019), psychological distress has been recognized as a result of toxic leadership (Asha and Snigdha,2019). Social science literature defines psychological distress as an emotional condition with depression and anxiety symptoms (Mirowsky \& Ross, 2002). According to Terry et al. (2020), people with psychological distress could change from healthy levels to anxiety, depression, demoralization, moodiness, aggression, and diminished personality. Of that kind, subjective states can worsen persons' emotional resilience and affect their ability to enjoy life and cope with pain, deception, and grief (Rose \& Mechanic, 2002).

Toxic leaders can strain and reduce their subordinates' emotional well-being through personal influence. Toxic leaders impair their subordinates' psychological well-being by intimidation, violations, embarrassment (Webster et al., 2016). Toxic leaders build a toxic workplace environment and highlight negative values that affect employees' psychological well-being, such as aggression, anxiety, and depression. Furthermore, Lipman-Blumen (2005) describes toxic leadership as an individual approach that focuses on personal interest and leads to severe employee performance, inspiration, career development, and health. Based on the statement above, it is assumed that:

H1. Toxic leadership positively affect psychological distress.

\section{Moderating effect of perceived organizational support.}

Employee emotional, mental health is ultimately caused by inadequate organizational support, specifically for employees' well-being (Bronston et al., 2017). According to Erdogan and Enders (2007), the failure of an organizational support dimension in which the leaders behave might lead to actions that can be understood. This highlights the fact that any 
discussion of the influence of toxic leadership style on employee psychological distress cannot be separated from consideration of the organizational support for these toxic leaders' actions.

Therefore, in this research, the Organization Support Theory is used as the underlying theory to analyze perceived organizational support. Perceived organizational support is derived from the Organizational Support Theory (Eisenberger et al., 1986; Eisenberger \& Stinglhamber, 2011; Shore and Shore, 1995). It was suggested that employees establish a general understanding of the degree to which they value their efforts and care for their wellbeing.

Reciprocal theory suggests that leaders' or employees' behaviour is motivated by organizational support policies (Rhodes \& Eisenberger, 2002). However, when the existing organization provides an effective coping mechanism and moral support to the worker, workers will not have poor emotional health, even though highly toxic leaders trigger employees. The critical function of the perceived support is to meet social and emotional needs and recognize the organization's readiness to reward its employees (Kanliang \& Qin, 2008).

In dark leadership literature, Mindy et al. (2013) found that the relationship between leadership and employee emotion is significantly moderated by high perceived organizational support. Thus, even though the employees experience the toxic leader, they would not have significant mental health issues if the perceived organizational support is vital. Furthermore, an effective coping mechanism tends to minimize emotional violence in the organization (George et al., 2009). It could also be hypothesized:

H2. The positive impact of toxic leadership on psychological distress is moderated by the perceived organizational support.

Thus this research proposed a theoretical framework that extended from Toxic Leadership Theory by adding outcomes variable ( psychological distress) and moderator variable (perceived organizational support) as show in Figure 1.

Figure 1: Conceptual framework

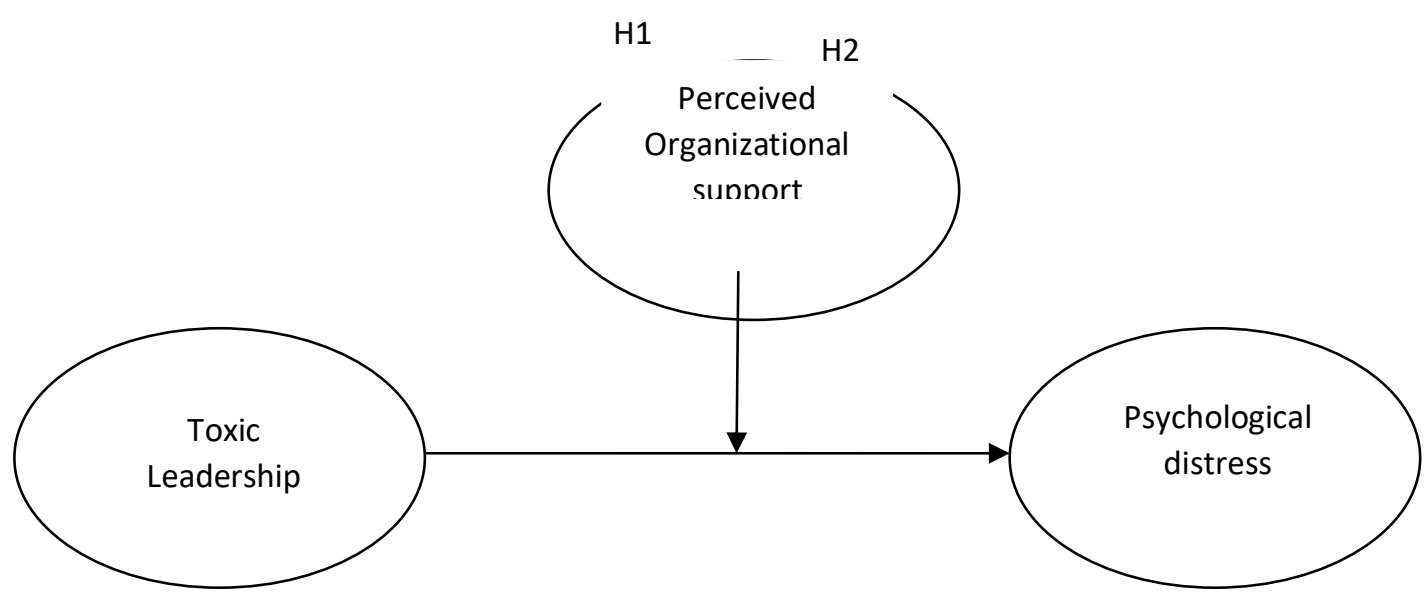




\section{Methodology}

\section{Participants}

The sample for this research comprised 450 academic staff from a public university in Malaysia. For gender, 238 (52.9\%) of respondents are male, and $212(47.1 \%)$ are female. The highest number of respondents was Senior Lecturer (170, $37.8 \%$ ), while 104 (23.1\%) were Associate Professor, 100 (22.2\%) Lecturer, and 76 (16.9\%) Professors. In terms of work experience, $146(32.4 \%)$ respondents had $1-5$ years of experience with the current immediate supervisor. In the meantime, 165 (36.6\%) respondents were between 6 and 15 years with the current immediate supervisor. The remaining 139 (30.9\%) respondents had more than 16 years of experience.

\section{Instruments}

In this research, a mixture of existing instruments from previous literature was used. A total of 54 items were used to evaluate the construct for this research. The questionnaire was divided into four sections. Section A consisted of demographic aspects such as gender, position, and experience with the current immediate supervisor. Section B examined the behaviour of the leaders during their leadership process. Perceived leadership style was measured through a toxic leadership scale from Pelletier (2010). The scale has seven dimensions, which outline the behaviour of the toxic leader. According to Tepper (2000), there have been only a few toxic leadership scales to date. Respondents were asked to rate their current immediate supervision behaviour through the scale. The scale ranged from $1=$ extremely useful to 7 = extremely harmful. Section $\mathrm{C}$ measured respondents' perceptions of the extent to which the organization values their contribution and well-being. Six items from Eisenberger et al. (2001) were used to determine perceived organizational support. Respondents were asked to indicate how much their organization valued them on the 7-point Likert scale from strongly disagreed to agree strongly. Besides, prior studies have provided evidence of this scale's high reliability and validity (e.g., Eisenberger, et al., 1990; Shore \& Wayne, 1993). It is a valid argument for adopting its scale for this research. Finally, Section D measured respondents' emotional reactions when interacting with their current immediate supervisor using Asha and Snigdha's (2019) scale. In this scale, three aspects of psychological distress, including loss of self-worth, agitation, and withdrawal, were measured. It consisted of 15 items whereby the respondent was asked to rate each item based on a seventh-point Likert scale, one $=$ strongly disagree, and $7=$ strongly agree. Nonetheless, after evaluating the measurement model, only 11 items were used for this research because the other four items had a loading factor of less than 0.5 .

\section{Procedure}

For this research, a multi-stage sampling technique such as cluster sampling and a simple random sampling technique was used. The reason for applying this technique is that this research's academic staff population is extensive and, therefore, a way of minimizing the population by dividing groups and subgroups into smaller groups until the researcher reaches the desired type or size (Marianne, 1992) of academic staff. For sample size, a statistical analysis approach with the application of G-Power 3.1 software (Faul et al., 2009) was used with an effect size setting of 0.15 in each of the dependent variables in the structured model with a significance level of 0.05 with a statistical power of 80 per cent, two predictors and the sample size needed was only 68. However, the population of academic staff in a public university in Malaysia was large; thus, a sample size of 450 was obtained for this research. 
Pretesting was conducted to define the limitations on the instructions, language, and items in the questionnaire (Zikmund, 2003) and establish content validity (Straub, 1989) by appointing an expert panel from the leadership field and language expert. After some adjustment of the questionnaire, the pilot study was conducted with 30 academic staff that is not involved as actual respondents. For the actual survey, the researcher contacted the Assistant Registrar of each faculty to verify the lecturers' details, such as their grade scale and whether they were still active in the university. Upon verification, an invitation to an online survey took place. The researcher used an email invitation and provided a link to the URL to respond to the study. However, there is concern about the rate of non-response. Therefore, the researcher contacted or approached the respondents through a reminder alert (email) multiple times to increase the response rate. Finally, the data were analyzed using Partial Least Square based Structural Equation Modelling version 3.2.7 for measurement model and structural model analysis.

\section{Results}

\section{Assessment of Measurement Models}

For Internal Consistency Reliability, the composite reliability values of the variables ranging from 0.914-0.989. As the costs are more than 0.7, according to Kline (2010), this sufficiently indicates that the items used to represent the construct have sufficient internal consistency. Convergent validity was used to identify factor loading and Average Variance Extracted (AVE), as suggested by Hair et al. (2011). Standardized loading items listed in Table 1 shows that the variables were considered to be significant as they met the threshold value of 0.70 by their expected factor (Hair et al.(2011), and all AVE values as shown in Table 1 were higher than the suggested value of 0.50 (Hair et al. 2011). The range is from 0.703 to 0.912 . It means that its construct reflected all of the variances of the items. 
INTERNATIONAL JOURNAL OF ACADEMIC RESEARCH IN BUSINESS AND SOCIAL SCIENCES Vol. 10, No. 12, 2020, E-ISSN: 2222-6990 @ 2020 HRMARS

\section{Table 1: Result of reliability test}

\begin{tabular}{|c|c|c|c|c|c|c|c|c|}
\hline $\begin{array}{l}\text { First-order } \\
\text { constructs }\end{array}$ & $\begin{array}{l}\text { Second- } \\
\text { order } \\
\text { constructs }\end{array}$ & Item & $\begin{array}{l}\text { Loading } \\
(>0.5)\end{array}$ & $\mathrm{M}$ & SD & $\begin{array}{l}\alpha \\
(>0.7)\end{array}$ & $\begin{array}{l}C R \\
(>0.7)\end{array}$ & $\begin{array}{l}\text { AVE } \\
(>0.5)\end{array}$ \\
\hline $\begin{array}{l}\text { Attack on } \\
\text { followers' esteem }\end{array}$ & & TL1 & 0.846 & 2.336 & 1.012 & 0.938 & 0.951 & 0.764 \\
\hline \multirow[t]{5}{*}{ (ESTEEM) } & & TL2 & 0.823 & & & & & \\
\hline & & TL3 & 0.869 & & & & & \\
\hline & & TL4 & 0.878 & & & & & \\
\hline & & TL5 & 0.905 & & & & & \\
\hline & & TL6 & 0.919 & & & & & \\
\hline Lack of integrity & & TL7 & 0.808 & 2.405 & 0.955 & 0.949 & 0.957 & 0.710 \\
\hline \multirow[t]{8}{*}{ (INT) } & & TL8 & 0.812 & & & & & \\
\hline & & TL9 & 0.849 & & & & & \\
\hline & & TL10 & 0.848 & & & & & \\
\hline & & TL11 & 0.852 & & & & & \\
\hline & & TL12 & 0.882 & & & & & \\
\hline & & TL13 & 0.823 & & & & & \\
\hline & & TL14 & 0.890 & & & & & \\
\hline & & TL15 & 0.815 & & & & & \\
\hline Abusiveness & & TL16 & 0.860 & 2.522 & 0.968 & 0.920 & 0.938 & 0.715 \\
\hline \multirow[t]{5}{*}{ (ABUSE) } & & TL17 & 0.829 & & & & & \\
\hline & & TL18 & 0.828 & & & & & \\
\hline & & TL19 & 0.849 & & & & & \\
\hline & & TL20 & 0.884 & & & & & \\
\hline & & TL21 & 0.822 & & & & & \\
\hline Social exclusion & & TL22 & 0.895 & 2.331 & 0.968 & 0.858 & 0.914 & 0.779 \\
\hline \multirow[t]{2}{*}{ (SE) } & & TL23 & 0.835 & & & & & \\
\hline & & TL24 & 0.917 & & & & & \\
\hline Divisiveness & & TL25 & 0.942 & 2.386 & 1.047 & 0.927 & 0.954 & 0.873 \\
\hline (DIV) & & TL26 & 0.937 & & & & & \\
\hline
\end{tabular}


INTERNATIONAL JOURNAL OF ACADEMIC RESEARCH IN BUSINESS AND SOCIAL SCIENCES Vol. 10, No. 12, 2020, E-ISSN: 2222-6990 @ 2020 HRMARS

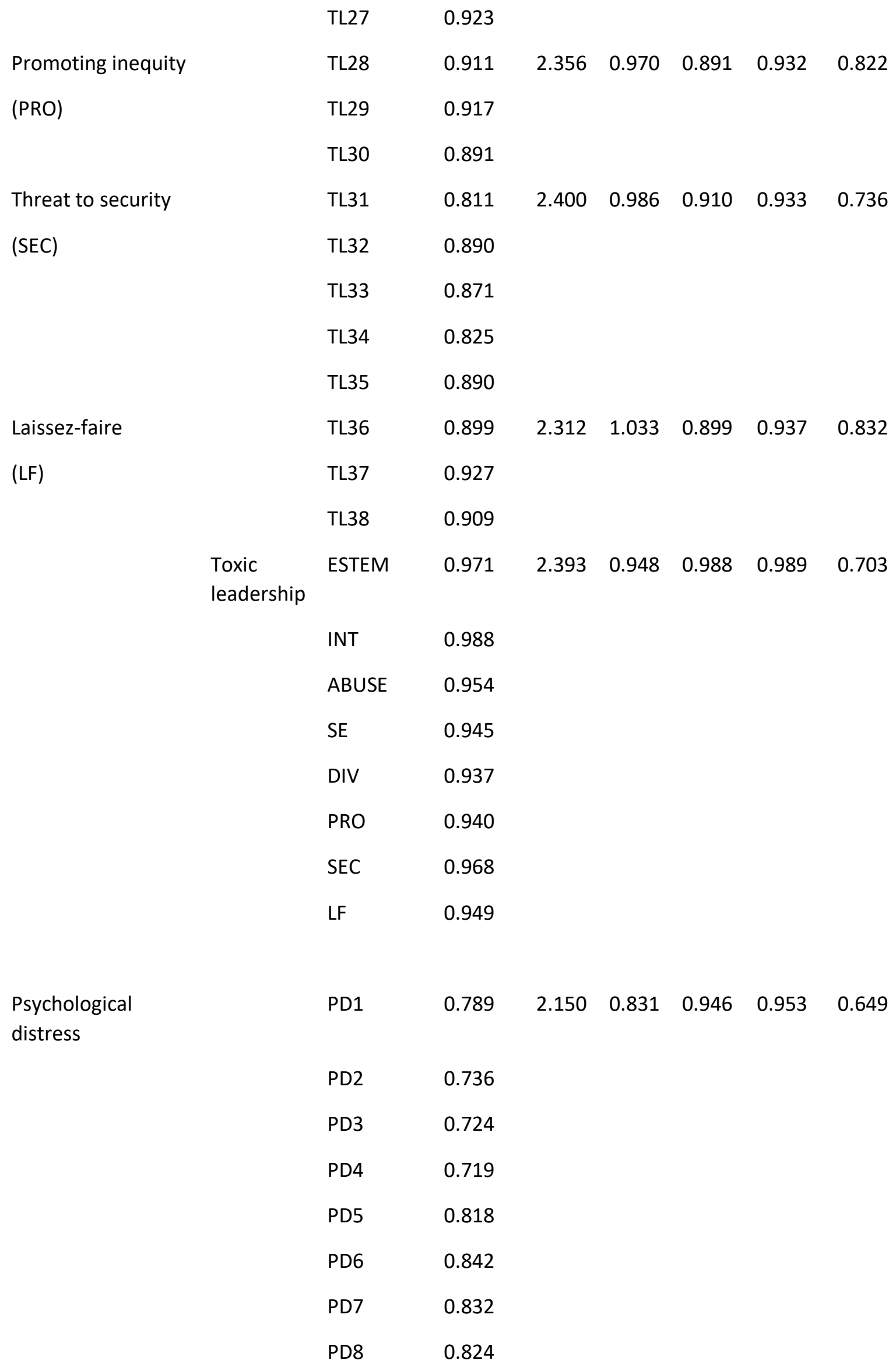




$\begin{array}{ll}\text { PD9 } & 0.841 \\ \text { PD10 } & 0.851 \\ \text { PD11 } & 0.867\end{array}$

Perceived

POS1

0.954

$2.924 \quad 1.510 \quad 0.977 \quad 0.981$

0.912

Organizational

Support

$\begin{array}{ll}\text { POS2 } & 0.948 \\ \text { POS3 } & 0.951 \\ \text { POS4 } & 0.968 \\ \text { POS5 } & 0.955\end{array}$

Note $M=$ Mean; SD=Standard Deviation, $\alpha=$ Cronbach's alpha; CR=Composite Reliability, $A V E=A v e r a g e$ Variance Extracted. All the factor loadings of the individual items are statistically significant $(p<0.01)$

Discriminant validity can be measured by employing three types of criterion: crossloading, Fornell-Larcker, and the Heterotrait-Monotrait ratio (HTMT). This research applied all the three forms of criterion to ensure that the definition or measurement is not related. For the cross-loading, a criterion for all the research variables fulfils the requirements. The analysis thus far provides evidence that the different constructs' indicators are not interchangeable for this research. Based on the Fornell-Larcker criterion analysis shown in Table 2, the AVE's square root on the diagonals, indicated by the bolded values, is higher than the correlation between the constructs (corresponding row and column values). Meanwhile, HTMT in this research shows that the values were lower than the suggested cut-off value of 0.85 , indicating that there was a tolerable level of discriminant validity (Table 3 ).

Table 2: Discriminant validity by Fornell and Larcker's

\begin{tabular}{lccc}
\hline & PD & POS & TL \\
\hline PD & $\mathbf{0 . 8 0 6}$ & & \\
POS & 0.046 & $\mathbf{0 . 9 5 5}$ & \\
TL & 0.496 & 0.074 & $\mathbf{0 . 8 3 8}$ \\
\hline
\end{tabular}

Note: Diagonal elements in bold show the square root of AVE while off-diagonal represent correlations between the constructs.

Table 3: Discriminant validity by Heterotrait-Monotrait ratio of correlations (HTMT)

\begin{tabular}{lccc}
\hline & PD & POS & TL \\
\hline PD & & & \\
POS & 0.044 & & \\
TL & 0.493 & 0.077 & 0 \\
\hline
\end{tabular}




\section{Structural model}

There are several stages proposed by Hair et al. (2017) for the analysis of structural models. It included assessing the structural model for collinearity issues, the evaluation of the significance and relevance of the structural model relationship ( $\beta$ ), the level of R2, and the effect size ( $f 2$ ). However, this study does not use $q 2$ because it is an optional stage.

For collinearity issues, the inner variable factor (VIF) values for independent variables (Toxic leadership) are less than 5 (Table 4). Thus, it shows that multicollinearity is not an issue for this research (Hair et al.,2017). Based on the path coefficient assessments in Table 5, it can be concluded that a toxic leader has a positive relationship with psychological distress. Toxic leaders foresee employees ' psychological distress in a meaningful way. This indicates that a toxic leadership style is directly related to the mental well-being of the follower. Thus, $\mathrm{H} 1$ is supported $(\beta=0.496, t=10.68)$. Meanwhile, the interaction terms of toxic leadership and perceived organizational support $(\beta 0.088, p>0.05)$ were not found to be significant. As a result, $\mathrm{H} 2$ perceived organizational support did not moderate the relationship between toxic leadership and psychological distress.

The predictive accuracy of the model can be tested through a coefficient of determination (R2) analysis. For this research, the model also indicates that toxic leadership accounts for 24.6 per cent of the psychological distress variance. As suggested by Cohen (1988), this analysis resulted in a moderate model with indices above 0.13 . Thus, toxic leadership could be adequately explained by psychological distress. For the assessment of effect size (f2), Table 5 shows a medium effect size (0.327) for toxic leadership and psychological distress. It shows that toxic leadership has a significant influence on academic staff psychological distress.

Table 4: Lateral Collinearity Assessment

\begin{tabular}{lc}
\hline Construct & Psychological distress (VIF) \\
\hline TL & 1.006 \\
\hline
\end{tabular}

Table 5: Hypothesis Testing

\begin{tabular}{|c|c|c|c|c|c|c|c|}
\hline $\begin{array}{l}\text { Hypothe } \\
\text { sis }\end{array}$ & Relationship & $\begin{array}{l}\text { Std. } \\
\text { Beta }\end{array}$ & $\begin{array}{l}\text { Std. } \\
\text { Error }\end{array}$ & t-value & Decision & $\mathbf{R}^{2}$ & $f^{2}$ \\
\hline $\mathrm{H} 1$ & $\begin{array}{l}\text { Toxic leadership } \\
\rightarrow \text { psychological distress }\end{array}$ & 0.496 & 0.046 & 10.68 & $\begin{array}{l}\text { Supporte } \\
\text { d }\end{array}$ & 0.246 & $\begin{array}{l}0.32 \\
7\end{array}$ \\
\hline $\mathrm{H} 2$ & $\begin{array}{l}\text { Toxic leadership* } \\
\text { perceived organizational } \\
\text { support } \rightarrow \text { Psychological }\end{array}$ & 0.088 & 0.081 & 0.202 & $\begin{array}{l}\text { Not } \\
\text { supporte } \\
\text { d }\end{array}$ & & \\
\hline
\end{tabular}

Note: $* * p<0.01, * p<0.05$

The Importance-Performance Map Analysis (IPMA) relevance is supported by Hair et al. ( 2017) as it can further clarify and discuss findings on the managerial implications. Table 6 shows the importance (total effects) and performance (index values) used for the IPMA. As shown in Figure 1, this study plotted the total effects scores and index values in a priority map. It can be observed that toxic leadership is a significant factor in explaining employee psychological distress based on higher importance values (0.443) than perceived organizational support (0.005). However, the performance of toxic leadership is lower than 
perceived organizational support. One of the IMPA goals is to identify predecessors with relatively high importance for the target construct (i.e., those with a robust total effect) and relatively low performance (i.e., low average latent variable scores). The aspects underlying these constructs represent potential areas of improvement that may need to receive significant attention (Figure 1). Overall, to reduce the psychological distress among employees, the managerial activities should prevent toxic leadership growth in the organization.

Table 6: IPMA for Psychological distress

\begin{tabular}{lcc}
\hline Latent construct & $\begin{array}{l}\text { The total effect of the } \\
\text { construct performance impact } \\
\text { (Importance) }\end{array}$ & $\begin{array}{c}\text { Index values } \\
\text { (Performance) }\end{array}$ \\
\hline Toxic leadership & 0.443 & 34.773 \\
Perceived organizational & 0.005 & 48.233 \\
support & & \\
\hline
\end{tabular}

Figure 2: IPMA (Priority Map) for psychological distress

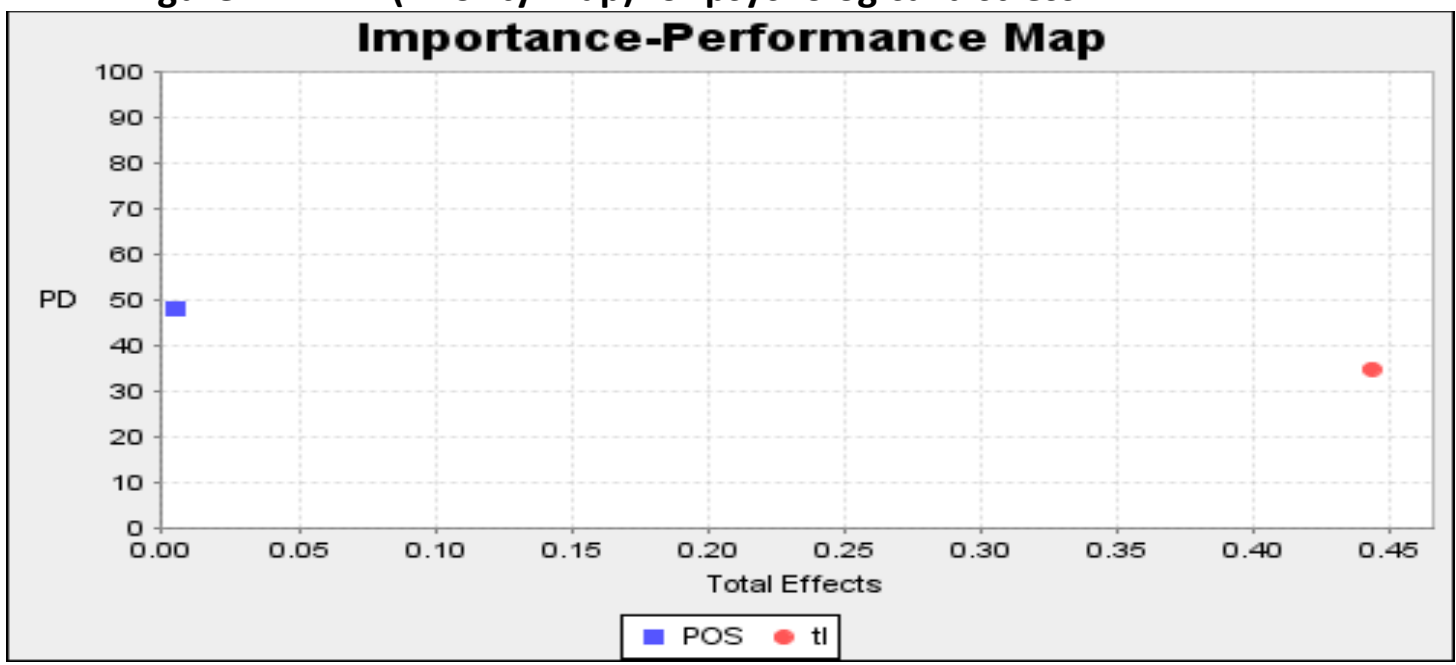

Key: $\quad$ POS: perceived organizational support, TL: toxic leadership, PD: psychological distress

\section{Discussion}

The toxic leadership conceptual framework (Figure 2) has been proposed and developed to unravel some of the mysteries surrounding the dark side of leadership among academic staff at a public university in Malaysia. In responses to the phenomenon, this framework extends by adding psychological distress and perceived organizational support variables (Organizational Support Theory).

Toxic leadership and psychological distress

This study proposed and examined the outcome of toxic leadership on the psychological distress of the academic staff. The relationship's investigation has shown that the academic staff reported on anxiety and depression while working with the toxic leaders. More specifically, the more leaders have a higher level of toxic leadership with their academic staff, the more they distress the leaders. This finding agrees with Rafferty and Restubog (2011) and Asha and Snigdha (2019), who revealed that workers who had experience with toxic leaders 
might suffer psychological distress over a certain period. These results provide further support for the hypothesis that toxic leadership has an adverse outcome on the subordinates' psychological well-being (Chen \& Kao, 2009; Chua \& Murray, 2015). Furthermore, Mahlangu (2014) also points out that educator leaders who seriously abuse power may cause psychological responses such as fear to the subordinates or parents. Within the particular context of higher education institutions, Smith and Fredricks (2019) note that when the leaders are implementing the fear tactics and giving a message that the staff will replaceable, it adversely impacts employees' psychological distress.

From the above discussion, it is possible to claims that employees with a negative perception of their toxic leaders are more likely to experience psychological distress because they probably do not have a better awareness of toxic behaviour, which may not help them in copping the emotional harm. Furthermore, Richman et al. (1992) noted that unaware of the toxic behaviour and agenda might cause psychological distress in the long term.

From a theoretical perspective, this research's positive relationship demonstrated that leaders who engage with malicious behaviour could cause psychological harm to their followers. One possible explanation was that employee psychological distress issues required a coping strategy for employees to deal with the emotional situation. For higher education in Malaysia, there is strong support from the human resource department, specifically a counselling department that guides emotional management. Nevertheless, the human resources department's incompetence in protecting employees emotional dissonance may build frustration among them. Low frustration resilience is the primary cause of depression (Seymour \& Miller, 2017). Finally, this research supported the above research question by contributing significant evidence on toxic leadership construct being impacted on psychological distress.

\section{Moderating effect of perceived organizational support}

Perceived organizational support represents recognizing an individual's contribution and wellbeing (Eisenberger et al., 1986). Hypothesis two was developed to test the moderating role of perceived organizational support in the relationship between toxic leadership and psychological distress. This study found that perceived organizational support has a nonsignificant relationship to buffer academic staff psychological distress within the public university, which contradicts the findings of previous studies (Gaetane et al., 2017; Jui and Yio, 2018; Li et al., 2016).

One possible explanation for its non-significant is lack of concern towards employees' welfare (Robaee et al.,2018) by the organization. For this research context, the academic staff that fails to manage their anxiety and depression effectively may lead to low self-esteem. Consequently, they find themselves hopeless in preventing a critical psychological situation. Despite that, if the academic staff believe that the organizations concerning their socioemotional needs, it may improve or stimulate their self-esteem by strengthening their perception of the ability to manage psychological distress. Conversely, unfairness, lack of supervisor support, and an unattractive reward system (Eisenberger et al., 1986) may develop a strain in greater intensity. Likewise, Organization Support Theory (Eisenberger et al.,1986) proposes that when one person entertains another nicely, the reciprocity norm requires the return of favourable treatment.

According to Lipman-Blumen (2010), toxic leadership is a process in which leaders possess destructive behaviour, inflict severe and enduring harm on their followers, thus do not have emotional support during their leadership process. The definition may explain the 
insignificant of moderating relationship for the high-perceived organizational support. Rhoades and Eisenberger (2002) indicated that one of the organizational supports is supervisor support. Supervisor support is defined as the degree to which employees form impressions that their superiors care about their well-being, for instance, managing subordinate emotion (Eisenberger et al., 2001). For this research, the positively perceived organizational support may not be concerned about managing employees' emotional exhaustion, but the leaders are more concerned about their destructive agenda.

Although this research is unable to support the previous study on organizational support, which found that perceived organizational support has a negative relationship with psychological effect (Kilo \& Hassmen, 2016; Kurtessis et al., 2017), there is also research have revealed a positive relationship on perceived organizational support and psychological strain. Asgari (2015) found that emotional disturbance was independent or not moderated by the amount of support received. Kurtessis et al., 2017) also indicate that high-perceived organizational support is more concerned about work issues and job tasks rather than socioemotional needs. Furthermore, Cropanzano and Greenberg (1997) identify that the structural aspect significantly influences perceived organizational support. In a public university, the ultimate goals are to build the university's international reputation. Thus, the university developed a structural aspect, such as policies that focused more on innovation and research output (Zafir \& Sheikh Muhammad Hizam, 2013). Therefore, high-perceived organizational support did not improve the academic staff's psychological health. Thus, this study has found that perceived organizational support has no moderating impact on the relationship between toxic leadership and psychological distress.

\section{Theoretical implications}

This research highlighted the previous findings and led to several important implications for the Toxic Leadership Theory. First, the toxic leadership literature is expanded through this research, which examined toxic leadership within the educational context in a non-western country, specifically in Malaysia. Even though toxic leadership outcomes are unfolded from western literature, the data should not be generalized to another region such as Malaysia. Moreover, toxic leadership is a phenomenon that has insufficient attention to employee wellbeing studies in higher education in Malaysia. As toxic leadership is vital for the employee well-being, the factors that can affect the growth of leaders toxicity, and the consequences are appropriate to be examined.

Secondly, to facilitate holistic research for the toxic leadership phenomenon, this study has adopted the Toxic Leadership Theory by collaborates the interaction between behaviour, organizational factors (perceived organizational support and toxic leadership), and individual factors (psychological distress) in a single research framework. On the other hand, the integrated framework can deliver a comprehensive understanding of the toxic leadership phenomenon compared to the standard research models that merely investigate toxic leaders' characteristics or behaviour. This research's main contribution is the findings that demonstrate that individual factors (psychological distress) are the most crucial predictor of toxic leaders' growth compared to the conducive environment, which supports the argument by Thoroughgood et al. (2012).

Thirdly, most previous studies in Malaysia have focused on constructive leadership's consequences on mental well-being (Bass, 1985; Brown \& Trevino, 2006; Eisenbeiss, 2012; Fry et al., 2005; Mahoney et al.,2009). In contrast, most destructive leadership studies, such as toxic leadership, have only been carried out in a small number of areas. Lipman-Blumen (2005) mentioned that external force plays a vital role in the toxic leadership process, but its 
eventual success depends on this dynamic's internal forces. As internal forces are crucial for the toxic leadership process, the factors that can influence toxic leadership, specifically on followers' mental well being are appropriate to be examined.

Fourthly, this study also found that toxic leadership could indeed contribute to employee psychological distress. Green (2014) stated that the research on toxic leadership and academic well-being is still scarce. Therefore, this research's findings expand to the body of knowledge to the academic staff psychological distress construct in a public university. Thus, this study's main highlight is testing toxic leaders' behaviour on academicians' psychological distress. When identifying toxic leaders' effect on academicians' psychological distress, it is suitable to look at the consequential destructive leader's behaviour with lasting damage to others.

Also, as far as it is known that the toxic leadership variable in this research is one of the first studies in a public university in Malaysia that examine the effect on academician psychological distress. Hence, the Toxic Leadership Theory application has so far been neglected in explaining emotional exhaustion among academicians in a public university. Based on the significant findings on the relationship, without doubt, this research shows the substantial applicability in Toxic Leadership Theory in explaining a further explanation on the issue of employee psychological distress in the workplace. This research also provides additional support beyond research previously conducted and further understands the outcome of toxic leaders among academic staff. An essential advantage of this research is its contribution to our knowledge of employee psychological distress. Broadening the behaviour of toxic leadership through employees' actual experiences with leader toxicity enables further research in the manifestation of employee psychological distress and psychological distress levels among academic staff in a public university in Malaysia.

Finally, this research extended the Toxic Leadership Theory by introducing an organizational construct, namely perceived organizational support. The most striking result of the analysis is that perceived organization support did not moderate the relationship between toxic leadership and psychological distress. In other words, the findings showed that perceived organizational support, if not efficient, could not lessen the amount of psychological strain. Perhaps this is the first study empirically attempted to integrate perceived organizational support in the relationship between toxic leadership and psychological distress. Thus, it is contributing an opportunity to identify why academicians still experience emotional disturbance.

\section{Practical contribution}

The findings of this study have several important implications for future practice in preventing toxic leadership in organizations. The organizations can educate the employees by promoting healthy to be independent who will challenge the toxic leaders and developed a positive working environment without losing control. Encouraging independence or promoting healthy should include giving employees the ability to do a specific action related to a toxic leader's oppression. Providing a wide variety of activities such as build trust in the workers, grant the employees the right in terms of workplace discrimination, and provide tools for reporting misconduct behaviour by the leaders.

There are also some strategies for breaking employees' psychological distress because of toxic leaders' behaviours. Organizations may adopt whistleblower policy as a mechanism for preventing unethical behaviour in the workplace. This policy could be beneficial for the victims of any destructive behaviour in the workplace. Indirectly, the victims feel protected when they disclosed the information and may reduce the emotional burden. Besides that, any 
wrongdoings can be valuable to the organization to take quick actions before the reputation damage. However, the organizations must have an adequate protection policy for individuals who possess the wrongdoing information. Otherwise, the whistleblowers may suffer a severe emotional disturbance due to a breakdown of trust.

Another strategy that can be implemented is educating on eliminating or overcoming anxiety and depression in the workplace. The organization can organize a seminar, forum, counselling, training, or launching a specific website about mental health conditions and coping strategy, alerting the employees about the severe impact of psychological distress in life by creating a simple infographic or brochure for the staff. Get an expert to check the validity of the content of the brochure for accurate information. Besides readings, face-toface sharing may help some other people get the information because each individual has different ways of learning styles. Thus, organizations can bring in speakers or consultants from outside of the organization to share depression situations and encourage all the employees to join the discussion session.

Besides that, the organization should create a social support environment among workers, such as companionship support. Social support can be done by implementing effective employee relations by encouraging them to access the more extensive social network and have friends within organizations. Nowadays, social support is a practical approach as it is associated with increased psychological well-being in the workplace. Also, it plays a vital role in lowering problems related to individual mental health. For this research, academic staff facing distress time and social support help them reduce their psychological distress. In contrast, individuals with low social support report more risk of mental health. As a whole, social support acts as a buffer to keep safe employees from psychological and physical health.

\section{Methodological Implication}

This study has a significant contribution in terms of statistical analysis. This research is among a very few toxic leadership studies that employ the Structural Equation Modelling -Partial Least Square (SMART-PLS) method to test the model. By applying SMART-PLS, this research examined more complex structural equation models with many constructs, such as the independent, consequences, and moderator variables of toxic leadership. Further, SMARTPLS is suited for theory development than for theory testing. In short, SMART-PLS not only provides a prediction among variables, but this method also can handle both reflective and formative constructs. As this study is considered a complex model with 54 items, the utilization of SMART-PLS is more appropriate and gives a valuable result on the findings.

\section{Recommendation for future research}

This research has developed that a toxic leadership style could predict employees' psychological distress at public universities in Malaysia. Another variable, such as coping strategy, can be reviewed further for toxic leadership outcomes. Lipman-Blumen (2005) pointed out that toxic leaders survive over time and are influenced by toxicity in the workplace. Toxic leaders stay may appears logical reasons to assume that toxic leaders tend to act harmful when an organization disregards ethical climate. Thus, future research should integrate a coping strategy as an essential factor in toxic leadership survival.

From literature, it is noticed that this research could be the first empirical research to analyze the proposed relationship in a public university in Malaysia, replication of this research in the future using a sample from other types of the organization could be a valuable 
attempt to confirm a vigorous conclusion of the findings. The toxic leadership phenomenon may vary depending on the types of organization and culture.

\section{Conclusion}

The most prominent finding to emerge from this study is examining the relationship between toxic leadership and psychological distress in Malaysia's public university. Realizing that the influence of toxic leadership is essential, the study also investigates the moderating effect between toxic leadership and psychological distress.

Several essential contribution points have identified from this research. Very little attention was paid to understand toxic leadership beyond the scope of administrative employees. For examples, most of the earlier work investigated this topic within the university administrative (Fahie, 2019), nurse (Labrague et al., 2020), human resource, banker and IT employees. Focusing exclusively on administrative employees potentially limits the perception of these toxic leadership behaviour. Compared to academic staff, they have articulated their understanding of leadership style out of their interests and not constrained by the norms of leaders. They are free to share anything, as the shared opinion does not belittle their immediate supervisor. Based on the two examples explained above, focusing on a different context may, therefore give a comprehensive understanding of the development of toxic leadership. The purpose of this research is indeed to understand the toxic leadership process among academic staff in higher education.

Toxic Leadership Theory was established as the primary theoretical underpinning used by all of the previous works that examined the topic. Due to the restricted constructs used in this theoretical model to analyze the toxic leadership, this research appeared to combine this theoretical model with other theory such as Organizational Support Theory (Eisenberger et al.,1986). Somehow by extending this theoretical model, it can strengthen the explanatory ability to, recognizing the coping strategy could improve the capacity of the theoretical model to explain the toxic leadership. Also, the Organizational Support Theory is adopted to predict employee psychological distress. This theory implies that individual wellbeing is affected by how the organization cares and values their emotional needs. Without fairness, support from supervisors and incentives, employees will not be able to see that organization has a strong emphasis on them.

On that basis, therefore this study indicates that further work is required to extend the existing model (i.e. toxic leadership theory) so that it can provide more substantial explanatory power to analyze the toxic leadership among academic staff. 


\section{References}

Ahmad, B. A., Tang, N., Van Dick, R., \& Mir, U.R. (2019). Authoritarian leadership, organizational citizenship behavior, and organizational deviance: Curvilinear relationships. Leadership \& Organization Development Journal, 40(5), 583-599.

Appelbaum, S. H., \& Roy, G. D. (2007). Toxins in the workplace: affect on organizations and employees. Corporate Governance, 7 (1), 17-28.

Arnold, K. A. (2017). Transformational leadership and employee psychological wellbeing: A review and directions for future research. Journal of Occupational Health Psychology, $22(3), 381-393$.

Asgari, S. (2015). The Influence of varied levels of received stress and support on negative emotions and support perceptions. Current Psychology, 35 (3), 386-396.

Asha, B., \& Snigdha, R. (2019). Toxic leadership: emotional distress and coping strategy. International Journal of Organization Theory \& Behavior, 22 (1), 65-78.

Bass, B. M. (1985). Leadership and performance beyond expectations. Free Press.

Bekir, E. K. (2020). The palgrave handbook of workplace well-being. Springer.

Bronston, T. M., Treena, G. F., T homas, W. J., Jie, S., \& Lin, Y. (2017). The effect of human resource practices on perceived organizational support in the people's Republic of China. The International Journal of Human Resource Management, 28 (9), 1261-1290.

Brown, M. E., \& Trevino, L. K. (2006). Ethical leadership: A review and future directions,

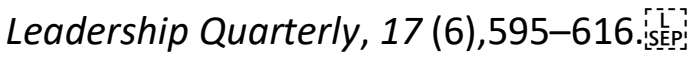

Chen, H., \& Kao, H.S. (2009). Chinese paternalistic leadership and non-Chinese subordinates' psychological health. The International Journal of Human Resource Management, 20 (12), 2533-2546.

Chua, S. M. Y., \& Murray, D. W. (2015). How toxic leaders are perceived: gender and information- processing. Leadership \& Organization Development Journal, 36 (3),292307.

Cohen, J. (1988). Statistical power analysis for the behavioural sciences (2nd ed.). Hillsdale, NJ: Lawrence Erlbaum Associates, Publishers.

Cropanzano, R., \& Greenberg, J. (1997). Progress in organizational justice: Tunneling through the maze. In Cooper, C.L., \& Robertson, I.T. International Review of Industrial and Organizational Psychology,12, 317-372. Wiley \& Sons.

Dobson, K. S., Szeto, A., \& Knaak, S. (2019). The working mind: A meta-analysis of a workplace mental health and stigma reduction program. The Canadian Journal of Psychiatry, 64 (1),39-47.

Dong, L. I. U., Hui, L., \& Loi, R. (2012). The dark side of leadership: A three-level investigation of the cascading effect of abusive supervision on employee creativity. Academy of Management Journal, 55 (5), 1187-1212.

Dotlich, D., \& Cairo, P. (2003). Why CEOs fail. Jossey Bass.

Ebrahim, Z. B., Mustapa, M. K., Mustakim, N. A., Mokhtar, N., \& Sauid, M. K. (2019). The influence of workplace support on job satisfaction among academic staff in five Malaysian public research universities. In Mohamad,N. M., Ahmad, I.M., Hashim, H., Abdullah, B., \& Baharum, M. (Eds.), Proceedings of the Regional Conference on Science, Technology and Social Sciences (RCSTSS 2016). Springer.

Eisenbeiss, S. A. (2012). Re-thinking ethical leadership: An interdisciplinary, integrative approach. Leadership Quarterly, 23 (5), 791-808.

Eisenberger, R., Fasolo, P., \& Davis-LaMastro, V. (1990). Perceived organizational support and employee diligence, commitment, and innovation. Journal of Applied Psychology, 75, 
51-59.

Eisenberger, R., \& Stinglhamber, F. (2011). Perceived organizational support: fostering, enthusiastic and productive employees. APA Books.

Eisenberger, R., Huntington, R., Hutchison, S., \& Sowa, D. (1986). Perceived organizational support. Journal of Applied Psychology, 7 (3), 500-507.

Eisenberger, R., Armeli, S., Rexwinkel, B., Lynch, P. D., \& Rhoades, L. (2001). Reciprocation of perceived organizational support. Journal of Applied Psychology, 86(1), 42-51.

Erdogan, B., \& Enders, J. (2007). Support from the top: Supervisors' perceived organizational support as a moderator of leader-member exchange to satisfaction and performance relationships. Journal of Applied Psychology, 92 (2), 321-330.

Fahie, D. (2019). The lived experience of toxic leadership in Irish higher education. International Journal of Workplace Health Management, 13 (3),341-355.

Faul, F., Erdfelder, E., Buchner, A., \& Lang, A. G. (2009). Statistical power analyses using G*Power 3.1: Tests for correlation and regression analyses. Behavior Research Methods, 41, 1149-1160.

Fry, L. W., Vitucci, S., \& Cedillo, M. (2005). Spiritual leadership and army transformation: theory, measurement, and establishing a baseline. Leadership Quarterly, 16 (5),835862.

Gaetane, C., Florence, S., Stephanie, D., \& Matthias, D. (2017). Perceived organizational support and employees' wellbeing: the mediating role of organizational dehumanization. European Journal of Work and Organizational Psychology, 26 (4),527-540.

George, A. Z., Kelly, Y., \& Joseph, P. (2009). Recognizing and overcoming toxic leadership. Journal of Nursing, 3 (5), 1-14.

Goldman, A. (2008). Company on the couch. Journal of Management Inquiry, 17 (3), 226-238.

Goldman, A. (2009). Destructive leaders and dysfunctional organizations: a therapeutic approach. Cambridge University Press.

Green, J. E. (2014). Toxic leadership in educational organizations. Education Leadership Review, 15 (1), 18-33.

Hair, J. F., Marko, S., Christian, M. R., \& Jeannette, A. M. (2011). An assessment of the use of partial least squares structural equation modelling in marketing research. Academy of Marketing Science, 40, 414-433.

Hair, J. F., Hult, G. T. M., Ringle, C., \& Sarstedt, M. (2017). A Primer on Partial Least Squares Structural Equation Modeling (PLS-SEM) (2nd ed.). SAGE, Thousand Oaks.

Hong, L., Yang, Z., \& Alison, W. (2019). Job satisfaction among hospital nurses: a literature review. International Journal of Nursing Studies, 94,21-31.

Hunt S. (1984). The role of leadership in the construction of reality in Kellerman B. (Ed.) leadership: multidisciplinary perspectives. Prentice-Hall.

Jui, C. C., \& Yio, Y. (2018). Hotel employee job crafting, burnout, and satisfaction: the moderating role of perceived organizational support. International Journal of Hospitality Management, 72,78-85.

Kanliang, W., \& Qin, S. (2008). The moderating impact of perceived organizational support on the relationship between technostress and role stress. Proceedings of 19th International Conference on Database and Expert System, 8 (2), 420-424.

Katherine, M. K., Ryan, N., Jolene, K., Sarah, R., Murray, B. S., Elliot, M. G., \& Jitender, S. (2014). Age, period, and cohort effects in psychological distress in the United States and Canada. American Journal of Epidemiology, 179(10), 1216-1227. 
Kelloway, E. K. (2017). Mental health in the workplace: towards evidence-based practice. Canadian Psychology/Psychologie Canadienne, 58 (1),1-6.

Kilo, R. A., \& Hassmen, P. (2016). Burnout and turnover intentions in Australian coaches as related to organizational support and perceived control. International Journal of Sports Science \& Coaching, 11 (2),151-161.

Kline, R. B. (2010). Principles and practice of structural equation modeling (3rd ed.). The Guilford Press.

Kurtessis, J. N., Eisenberger, R., Ford, M. T., Buffardi, L. C., Stewart, K. A., \& Adis, C. S. (2017). Perceived organizational support: A meta-analytic evaluation of organizational support theory. Journal of Management, 43 (6), 1854-1884.

Li, X., Qian, J., \& Han, Z. R. (2016). Coping with abusive supervision: the neutralizing effects of perceived organizational support and political skill on employees' burnout. Current Psychology, 35 (1), 77-82.

Lipman-Blumen, J. (2010). Toxic leadership: A conceptual framework. In Bournois, F., Duval-Hamel, J., Roussillon, S., \& Scaringella, JL. (Eds.), Handbook of Top Management Teams (pp. 2-28). Palgrave Macmillan.

Lipman-Blumen, J. (2005). The allure of toxic leaders: Why we follow destructive bosses and corrupt politicians-and how we can survive them. Oxford University Press.

Loraleigh, K., \& Karen, J. (2011). North American perspectives on hostile behaviors and bullying at work. In Einarsen, S., Hoel, H., Zapf, D., \& Cooper, C., Bullying and emotional abuse in the workplace (pp. 32-62). Taylor \& Francis Group.

Lubit, R. (2004). The tyranny of toxic managers: Applying emotional intelligence to deal with difficult personalities. Ivey Business Journal Online, 68 (4),1-8.

Mahlangu, V. P. (2014). The effects of toxic leadership on teaching and learning in South African township schools. Journal of Social Sciences, 38 (3), 313-320.

Mahoney, K. T., Buboltz, W. C., Jr., \& Igou, F. (2009). The second act of the leadership quarterly: A content analysis of volumes 11-19. Louisiana Tech University.

Marianne, F. G. (1992). Sampling in a suitcase: multistage cluster sampling made easy. Gifts: 20 Great Ideas for Teaching Sociology, 20 (4), 285-287.

Mindy, K. S., Simon, L., Restubog, D., Robert, E., \& Thomas J. Z. (2013). Blaming the organization for abusive supervision: the roles of perceived organizational support and supervisor's organizational embodiment. Journal of Applied Psychology, 98 (1),158-168.

Mirowsky, J., \& Ross, C. E. (2002). Selecting outcomes for the sociology of mental health: Issues of measurement and dimensionality. Journal of Health and Social Behavior, 43,152-170.

Mitchell, K., \& Elizabeth, H. (2009). Toxic workplace! managing toxic personalities and their systems of power. John Wiley \& Sons.

Nada, E., \& Ruth, M. (2020). Workplace issues in the context of Aldous Huxley's Brave New World: Mental health problems, cannabis and the division of labour. Transnational Corporations Review, 12 (2),106-125.

Natesha, S., \& Imani, F. (2019). Conflict in the workplace: a 10-year review of toxic leadership in higher education. International Journal of Leadership in Education,_15 (1), 106-115.

Ozlem, O., Ugurluoglu, O., Kahraman, G. A., \& Keziban. (2017). A study on toxic leadership perceptions of healthcare workers. Global Business and Management Research, 9(1), 12-23.

Pahlevan, S., Ahadzadeh, S., Sharif, A.S., \& Nia, H. (2018). Mediating role of psychological 
wellbeing in the relationship between organizational support and nurses' outcomes: A cross-sectional study. Journal Advanced of Nursing, 74, 887- 899.

Pelletier, K. L. (2010). Leader toxicity: An empirical investigation of toxic behaviour and rhetoric. Leadership, 6 (4),373-389.

Rafferty, A. E., \& Restubog, S. L. D. (2011). The influence of abusive supervisors on followers' organizational citizenship behaviours: the hidden costs of abusive supervision. British Journal of Management, 22 (2),270-285.

Rhoades, L., \& Eisenberger, R. (2002). Perceived organizational support: a review of the literature. Journal of Applied Psychology, 87 (4), 698-714.

Richman, J. A., Flaherty, J. A., Rospenda, K. M., \& Christensen, M. (1992). Mental health consequences and correlates of medical student abuse. Journal of the American Medical Association, 26 (5), 692-694.

Robaee, N., Atashzadeh-Shoorideh, F., Ashktorab, T., Baghestani, A., \& Barkhordari, M. (2018). Perceived organizational support and moral distress among nurses. BMC Nursing, 17 (2),1-7.

Rose, S. M., \& Mechanic, M. B. (2002). Psychological distress, crime features, and help-seeking behaviors related to homophobic bias incidents. American Behavioral Scientist, 46 (1), 14-26.

Rubenstein, A. L., Eberly, M. B., Lee, T. W., \& Mitchell, T. R. (2018). Surveying the forest: A meta-analysis, moderator investigation, and future-oriented discussion of the antecedents of voluntary employee turnover. Personnel Psychology, 71, 23-65.

Schyns, B., \& Schilling, J. (2013). How bad are the effects of bad leaders? A meta-analysis of destructive leadership and its outcomes. The Leadership Quarterly, 24 (1),138-158.

Seymour, K. E., \& Miller, L. (2017). ADHD and depression: The role of poor frustration tolerance. Current Developmental Disorder Reports, 4, 4-18.

Shore, L. M., \& Shore, T. H. (1995). Perceived organizational support and organizational justice. In Cropanzano, R., \& Kacmar, K. (Eds.), Organizational Politics, Justice, and Support (pp.149-164). Quorum.

Shore, L. M., \& Wayne, S. J. (1993). Commitment and employee behavior: Comparison of affective organizational commitment and continuance commitment with perceived organizational support. Journal of Applied Psychology, 78, 774-780.

Smith, N., \& Fredricks, L. I. (2019). Conflict in the workplace: a 10-year review of toxic leadership in higher education. International Journal of Leadership in Education, 1-14.

Straub, D. (1989). Validating instruments in MIS research. MIS Quarterly, 13 (2), 147-169.

Tepper, B. J. (2000). Consequences of abusive supervision. Academy of Management Journal, 43,178-190.

Tepper, B. J., \& Henle, C. A. (2011). A case of recognizing distinctions among constructs that capture interpersonal mistreatment in work organizations. Journal of Organizational Behavior, 32, 487-498.

Terry, A. B., Chris, S., Alla, S., Alice, P., Karen, W., Ana, M. L., \& Pavani, C. (2020). Randomized controlled trial of supportive care interventions to manage psychological distress and symptoms in Latinas with breast cancer and their informal caregivers. Psychology \& Health, 35 (1), 87-106.

Thoroughgood, C. N., Padilla, A., Samuel, T. H., \& Brian, T. W. (2012). The susceptible circle: A taxonomy of followers associated with destructive leadership. The Leadership Quarterly, 23 (5), 897-917. 
Vickers, M. H. (2006). Towards employee wellness: Rethinking bullying paradoxes and masks. Employee Responsibilities and Rights Journal, 18 (4),267-281.

Webster, V., Brough, P., \& Daly, K. (2016). Fight, flight or freeze: Common responses for follower coping with toxic leadership. Stress Health, 32, 346- 354.

Whicker, M. L. (1996), Toxic Leaders: When organizations go bad. Doubleday.

$\mathrm{Wu}, \mathrm{T}$. Y., \& Hu, C. (2009). Abusive supervision and employee emotional exhaustion: dispositional antecedents and boundaries. Group \& Organization Management, 34 (2), 143-169.

Zafir, M. M., \& Hizam, S. M. S. K. (2013). Stress among Malaysian academic: A conceptual study. International Journal of Academic Research in Business and Social Sciences, 2 (1), 196-211.

Zikmund, W. G. (2003), Business Research Methods (7th ed.). Thomson. 